usefulness of ambulatory blood pressure monitoring. J Am Soc Nephrol 2004; 15 Suppl 1: S30-33.

3. Pickering TG, Coats A, Mallion JM, et al. Blood pressure monitoring. Task force V: white-coat hypertension. Blood Press Monit 1999: 4(6): 333-341.

\section{Use of email for consulting with patients in general practice}

In this interesting editorial, Helen Atherton discusses the use of emails for consulting with patients. ' The consultation is at the core of general practice. With the patient in front of us in the consulting room, we are able to interact and engage with them, develop a rapport, and nurture the doctorpatient relationship. We have the opportunity to get to know our patients along with their families on an individual and personal level. Face-to-face, we also learn about our patients from their non-verbal cues, demeanor, and attire. This assists us in understanding our patients and their needs as a whole, beyond their health needs. When I signed up to GP training, I did so because I was excited about this idea of delivering a personal and holistic service. A few lines in some form of email consultation seems incomplete, impersonal, and lacks the patient-centeredness, family-centeredness, and holism that GPs are encouraged to aspire towards.?

Hajira Dambha,

Academic Clinical Fellow in Primary Care, University of Cambridge.

E-mail: hajiradambhaladoctors.org.uk

\section{REFERENCES}

1. Atherton $\mathrm{H}$. Use of email for consulting with patients in general practice. Br J Gen Pract 2013; 63(608): 118-119.

2. Goodwin N, Dixon A, Poole T, et al. Improving the quality of care in general practice. Report of an independent inquiry commissioned by The King's Fund. London: The King's Fund, 2011. wuw. kingsfund.org.uk/publications/improving-qualitycare-general-practice laccessed 8 Apr 2013).

\section{Sharing control of appointment length with patients in general practice}

I was interested to see Rod Sampson's article; many years ago I read something similar, and decided to try it myself, albeit without the post-appointment interviews. We offered my patients 5, 10, 15, or 20-minute appointments; it worked very well; I was pleasantly surprised. Patients had a good idea of how much time they would need; very few requested the longer 'slots' so my fears of being overwhelmed proved unfounded.

We did not continue the experiment because at the time I had a policy of accepting phone calls from patients; this interrupted the consultation lalthough if I let the phone ring more than three times the receptionist understood that I was not going to answer) but saved having to ring back, with the problems that engendered for the patient in terms of having to stay by the phone for an unpredictable period of time. However, what happened was that for each phone call, I ran that little bit late, so if there were several calls the later patients were kept waiting for longer than I (or they) would have wished.

All this was long before QOF, but there would seem to be no reason why such a system could not work well, with an extra few minutes added on for those doctorcentred elements. Thus the patient would feel they had had a fair hearing, and the doctor would not feel pressured into trying to squeeze the QOF components into a 10-minute slot if the patient's agenda was a long one. After all, who tells the patient that the appointment is for 10 minutes? With this system, the patient knows exactly how long they've got. Also, the doctor would not have in the back of his or her mind the oftquoted fear of the patient who brings a list, surgeries would not overrun, waiting rooms would not be full of disgruntled patients; the benefits would seem considerable on both 'sides'.

The obvious counter-argument is that surgeries would take longer, or that fewer patients would be seen. That was not the case when I tried it; Sampson's article makes no mention of this aspect; clearly more information is needed, but in the meantime, why not try it?
Chris Barry,

FRCGP, Recently retired GP, 96 The

Bramptons, Swindon, SN5 5SL.

E-mail: chrisbarry194510gmail.com

\section{REFERENCE}

1. Sampson R, O'Rourke J, Hendry R, et al. Sharing control of appointment length with patients in general practice: a qualitative study. $\mathrm{Br} \mathrm{J}$ Gen Pract 2013; DOI: 10.3399/bjgp13X664234.

DOI: 10.3399/bjgp13X667097

\section{The numbers needed to inform consent?}

Is consent ever informed if the numbers that describe risk remain a mystery to most people? Better ways and numbers ${ }^{1}$ to explain overall benefits and risks like numbers needed to benefit (NNB) and numbers needed to damage (NND) are welcome, but may fail to inform most decisions. Doctors often don't know the numbers needed to treat (NNT) and numbers needed to harm (NNH) or don't explain the true benefits and harms of tests and treatments. Patients usually consent with only a poor understanding of their risks.

Patients usually overestimate the benefit of treatments. ${ }^{2}$ For example, many people using statins or antihypertensive's believe they are substantially reducing their risk of heart attack or stroke. Assuming that the treatment is safe and used for 5 years, only a few patients would take a drug if they thought that they had a 5\% chance or less of benefiting (NNT 20). Half of the patients would take a drug if the chance of them benefiting was 20\% (NNT 5). If the benefit was $5 \%$ or less then the number of patients willing to take a preventive drug was doubled if their doctor recommended the treatment. Most interventions are not that good.

Different doctors and patients cope with the same risk differently and the subsequent management of the same conditions varies widely. ${ }^{3}$

How can understanding of risk and consent become better informed?

GPs need to know and explain the frequency of benefits and harms of the tests and treatments that they recommend to patients. To be able to do this risk scores like NNT, NNH, NNB, NND for tests and treatments need to be easily 